\title{
The Uneasy Case for Parsimony in (Law and) Economics: Conceptual, Empirical and Normative Arguments
}

\author{
${ }^{1}$ Northumbria University School of Law, Newcastle, United Kingdom, E-mail: peter.cserne@northumbria.ac.uk. \\ https://orcid.org/0000-0002-4302-1931.
}

\begin{abstract}
:
Taking Guido Calabresi's discussion of preferences and value judgements in The Future of Law and Economics as a starting point, this paper analyses some conceptual difficulties, epistemic benefits and normative uses of parsimonious economic analyses of "tastes and values." First, the paper shows that it is not only possible to analyse and model all the richness of "tastes and values" in terms of rational choice theory with intellectual honesty and epistemic benefit. In fact, economists and economically inspired legal scholars have been doing this for a while. Second, it discusses three arguments that economists can mount in support of parsimonious models. Third, it shows that in spite of these benefits the merits of such an exercise in parsimony do not always clearly outweigh its drawbacks. In doing so, the paper distinguishes three types of limits of such parsimonious modelling.
\end{abstract}

Keywords: law and economics: methodology, vales and morality in economic theory, Guido Calabresi, parsimony in economic theory

DOI: $10.1515 / g j-2019-0001$

In the last two chapters of his masterful The Future of Law and Economics (Calabresi 2016), Guido Calabresi provides a modest and constructive critique of what he takes to be the standard economic account for tastes and values. He summarises the main claim of these chapters, respectively, as follows. Chapter 7 is about "the actual and unavoidable existence of value judgements underlying most economic analysis" (ibid, 22). Chapter 8 emphasises and illustrates "the capacity of economic analysis, under quite traditional economic theory assumptions, to give guidance as to the desirability of a variety of tastes and values" (ibid, 22).

I agree with the first claim, although we might disagree about the nature of value judgements. ${ }^{1}$ In fact, I shall argue below, in line with some previous commentators, that the way Calabresi discusses value judgements in terms of moral costs is problematic. I also have some quibbles about Calabresi's second claim and its elaboration in chapter 8 , namely about the intelligibility and the usefulness of the "guidance" allegedly given by economic analysis.

While I am critical of the way Calabresi conceptualises value judgements in this book, I realise that there may be reasons for it as part of an argumentative strategy. It is easy to recognise that the book has been written in response to the dominant mode law and economics is currently practiced in the USA and wants to change the direction of this scholarship. This is not a purely academic agenda because, as Calabresi rightly says, law and economics scholarship matters for legal and policymaking practice. This context and rhetorical purpose may have motivated what I consider problematic terminology. But this argumentative strategy may turn out to be also mistaken, in particular, self-defeating, if it turns out that parsimonious models have a strong performative effect in the sense of not only re-conceptualising but crowding out values and motivations that are, in ordinary terms, not matters of costs and benefits.

My main point in this paper is, however, not about rhetoric but about the methodology of law and economics. The topic I am interested in is an underlying, largely implicit theme of the entire book: how the richness of the human experience, or in J.S. Mill's words, "the whole unanalysed experience of the human race" (cited in Calabresi 2016, 1) is, can be or perhaps should be accounted for in terms of the categories of mainstream economics and law and economics (L\&E). More specifically, this paper discusses, in somewhat more abstract terms than Calabresi's book, how selfishness and altruism, calculating instrumental rationality and adherence to values, context-dependent concerns about the scope of markets and other allocation mechanisms, in sum, human motivation and action can be or perhaps should be accounted for in terms of (possibly non-standard) preferences and (possibly non-standard) costs. 
The argument proceeds in three steps. First, I shall argue that it is not only possible to analyse and model all the richness of "tastes and values" in terms of preferences and costs without intellectual dishonesty but economists and L\&E scholars have been doing this for a while (Kliemt 1990; Vanberg 2008). Second, I shall present three arguments that economists can mount in support of such parsimonious models. Third, I shall show that the overall benefits of such an exercise in parsimony are not always clear and point at several limits of such parsimonious modelling. In particular, I shall raise doubts about the conceptualisation of value judgements as mere preferences or as moral costs. This, however, does not mean an outright rejection of rational choice models. Rather, the main contribution of the paper lies in advancing the discussion about the merits and problems of such models and distinguishing conceptual, empirical, and normative aspects. Once the various kinds of pro and con arguments are identified, it is easier to realise that the merits and demerits of parsimony play out differently in different contexts: what is legitimate or desirable in some contexts and for some purposes is mistaken or narrow-minded in others. Thus, the paper suggests that there is no single right answer to the question whether parsimonious models are appropriate: it is an uneasy case.

\section{Rational choice modelling of tastes and values: It is possible and economists are already doing it}

Calabresi's critique of economic analyses of values builds on his understanding of merit goods as moral limits to markets and these moral limits to markets, in turn, as deriving from "moral preferences" (ibid, Ch 2-4). This is the immediate context of his conceptualisation of values as preferences. Calabresi's discussion of merit goods, linked to the moral costs of commodification, is quite standard economic analysis, both in its method and conceptual apparatus. Taken at face value, the early chapters of the book seem to imply that conventional morality (of a particular society or political community, here almost always implicitly the USA) guides or should guide public decisions. In turn, economists have no other task than to register those moral costs, including their changes. Later, however, he notices a paradoxical or inconsistent attitude in how economists treat tastes and values in their analysis, both pursuing and refusing (or denying) the evaluation of individual preferences (Calabresi 2016, 91 and 131-2). He is catching economists at doing things they claim not doing. Yet, crucially, he addresses them on what he takes to be their own terms: costs and benefits. In the last chapter, he suggests certain values that should be inculcated in society. There are some surprising suggestions there for the kind of values that he sees as worthwhile cultivating. ${ }^{2}$ To be sure, this "radical and challenging" idea of "Taste Shaping" (Calabresi 2017, 178) could be seen, less radically, as a hypothetical or conditional one, based on certain highlevel societal goals and values that are taken as given.

It is also interesting to note that this discussion takes place in the context, or perhaps shadow, of behavioural law and economics (BLE). While Calabresi praises BLE at several points, he still seeks to convince (lawyer)economists of the old guard. That's why he bases his proposals in chapter 8 on "quite traditional economic theory assumptions" (Calabresi 2016, 22). In the next section, I will examine some of these assumptions. Elsewhere, I have argued that the rise of BLE works as a litmus test on epistemic, methodological and normative commitments of L\&E scholars and economists more generally. The growing empirical evidence on human behaviour reveals dividing lines, manifests latent tensions and polarizes debates between various camps or traditions in both positive and normative (law and) economics (Cserne 2017).

The main argument of this section, however, is that there are no unsurmountable analytical difficulties in modelling all the richness of "tastes and values" in a quite traditional manner in (law and) economics. In fact, economists and L\&E scholars have already been doing this for a while, including analysing "moral costs" and "moral externalities". Thus, Calabresi's call has already been answered.

There is little doubt that it is possible to model tastes and values, including altruism, rule-following and adherence to moral norms with the analytical tools of mainstream economics, i. e. in terms of rational choice and also defining preferences as stable and self-regarding. It all depends on how preferences are conceptualised and what sort of constraints to maximisation are included in the models. As a matter of phenomenological description, ordinary human beings are guided by a wide range of motivations, both prudential and moral: perceived self-interest, norms of reciprocity, moral principles, respect for rules, fear of punishment or ostracism, etc. Their behaviour is also driven by emotions, habit and custom, or sheer physiological stimuli. Yet, economic theory often works under the assumption and some economists even explicitly argue that "[m]an is eternally a utility-maximizer, in his home, in his office - be it public or private - in his church, in his scientific work, in short, everywhere." (Stigler 1982, 35)

Gary Becker's work, including his papers on irrationality, altruism, preference interdependencies or his joint article with George Stigler on "tastes" (Stigler and Becker 1977), ${ }^{3}$ provides classic examples of modelling complex individual behavioural patterns as well as social phenomena based on parsimonious assumptions of 
rationality, self-interest and equilibrium. For instance, acquired taste, addiction, racial segregation and education are all explained by models of personal and social human capital. The basic idea is that "[t]he utility that people derive from what they do in the present depends on what they did and what was done to them in the past, and on what other people are currently doing." (Elster 1997, 750) ${ }^{4}$

Economic models of morality have been developed further in the last decades, in an effort to account for complex patterns of rule-following, altruism, and cooperation, as documented empirically in both field research and laboratory experiments. The sheer volume of this literature makes it impossible to summarise it so I just refer to a number of characteristic ways such modelling can proceed. Some of these models take morality as given and explicate it in terms of "moral preferences" (Rabin 1993). They redefine preferences in an ad hoc manner, by attaching utility to norm-conformity itself, and analyse the dynamics of various mixed populations of selfish and norm-guided agents. In other words, they do not want to reduce non-instrumental reasons to instrumental ones but rather analyse the social consequences of various preference mixes. Other models go further and try to account for preference formation in rational choice terms, i. e. as sophisticated versions of rational self-interested action. Analytically, this can be done in at least three ways.

"The preferences of an agent $A$ can be traced back to a rational choice"

1. "by another agent $B$ for the purpose of shaping or changing $A$ 's preferences",

2. "by $A$ for some purpose other than preference acquisition", or

3. "by $A$ for the very purpose of acquiring those preferences" (Elster 1997, 753)

Examples of (1) include moral education and indoctrination. For instance, Dorothea Kübler suggests a model where social norms are regulated collectively through "changing the meaning or the reputational value of following a norm" (Kübler 2001, 449). Economic models of the expressive role of law (Sunstein 1996) may also belong here. Some variants of these models will be discussed below.

An example of (2) is to explain moral behaviour as a signalling mechanism in a repeated-game framework. In these models, people comply with social norms in order to sustain their reputation for trustworthiness (Posner 2000).

Analytically, these are easy cases. More difficult is (3). With regard to intertemporal preferences, Elster argues that "the very idea" is conceptually incoherent:

We cannot expect people to take steps to reduce their rate of time discounting, because to want to be motivated by long-term concerns ipso facto is to be motivated by long-term concerns, just as to expect that one will expect something to happen is to expect that it will happen. (Elster 1997, 754)

Yet, one can meaningfully speak of second-order, or more generally meta-preferences and thus construct a model of endogenous preference change. If we give up on the idea of $A$ as a single agent with a single set of preferences and allow for multiple selves $\left(A_{1}, A_{2}, \ldots\right)$, we can interpret moral conduct as the rule-guided behaviour of a lower-level self, directed by instrumental considerations of a higher-level self. In a number of papers, Robert Cooter $(1998,2006)$ analyses morality in this vein, as a technique of self-governance (self-control and self-improvement) by self-interested rational individuals. ${ }^{5}$

Rather than further discussing these lines of economic modelling of "tastes and values" in general, let me illustrate how this economic understanding of morality enters mainstream L\&E. L\&E scholars not only explicitly acknowledge "moral externalities" but argue for including them in an instrumentalist legal policy based on a social welfare calculus. Thus, Steven Shavell argues that "the existence of moral beliefs should itself influence the design of the law, given that moral beliefs constitute tastes the satisfaction of which raises individuals' welfare" (Shavell 2002, 255). He compares law and morality as two mechanisms for the regulation of conduct and discusses

their theoretically optimal domains - [i. e.] where morality alone would appear to be best to control behaviour, [...] where morality and the law would likely be advantageous to employ jointly, and [...] where solely the law would seem to be desirable to utilize. (Shavell 2002, 227)

In a related paper, Shavell and Louis Kaplow suggest a theory as to what kind of moral system would be economically efficient, i. e. how moral sanctions (guilt) and rewards (virtue) should "be employed to govern individuals' behaviour if the objective were to maximize social welfare" (Kaplow and Shavell 2001, 1). As these examples suggest, mainstream L\&E scholars openly and without scruples do what Calabresi $(2016,91)$ takes them to be "supremely qualified to do", namely "analyse why [...] some tastes and values are, in fact, preferable (in an economic sense) to others."

In a recent paper on "Moral Commitments in Cost-Benefit Analysis", Posner and Sunstein (2017) explicitly discuss how and why moral externalities should be included in such a welfarist calculus for public policy 
purposes. Their analysis is not a mere academic exercise - they are suggesting methods of making and justifying public decisions that have serious real-world consequences. They argue that third-party preferences, motivated by moral commitments, and measured by willingness to pay, should, as far as practicable, be part of any costbenefit analysis pursued by administrative agencies. ${ }^{6}$ For instance, the question how much social benefits are attached to protecting dolphins depends not only on the "welfare effects" but also on the "moral effects" on those who care about dolphins. ${ }^{7}$

Such welfarist analysis of moral arguments has been criticised by previous commentators on Calabresi's book (e. g. Harel 2017). When pressed, both Calabresi $(2017,171)$ and Posner and Sunstein $(2017,1,4)$ are cautious not to claim that all moral views or value judgements are "really" reducible to benefits and costs in welfarist terms. They acknowledge that there may be welfare-independent moral reasons for certain policies. They also acknowledge that there are moral, as well as legal, reasons against including some third-party preferences in a welfarist calculus. Some such preferences are "off-limits" for the purposes of public policy, and Posner and Sunstein suggest identifying those by invoking provisions of the (US) Constitution and other laws. For instance, they argue that as a matter of law, in a cost-benefit analysis pursued by a US government agency, racist preferences should not be taken into account for the simple reason that this would be illegal and perhaps unconstitutional. $^{8}$

Similar ad hoc arguments about the limits to wealth-maximisation have been invoked by Posner père when arguing that certain practices, such as suicide pacts, private discrimination on racial grounds, or the flogging of prisoners, which seem efficient in the sense of wealth-maximising, nonetheless "offend the sense of justice of modern Americans, and are all to a greater or lesser (usually greater) extent illegal" (Posner 1998, 31). He took these to illustrate the general claim that "there is more to justice than economics" (ibid). Positive law and the constitution are, of course, contingent and crude measures of moral rightness. They might provide sensible rough proxies in practice but in these discussions they are not explicitly analysed in such terms. The corresponding question whether there are moral reasons to oppose these practices, above and beyond what is enshrined in positive law, is not addressed directly either by Posner fils and Sunstein (2017) or Calabresi (2016, 2017). In fact, the question is not even raised. Are there reasons for such reluctance?

As it happens, there is philosophically informed or at least normatively sensitive L\&E literature that argues against grounding legal decisions and legal policy in moral externalities. In a couple of papers, using the example of same-sex marriage, ${ }^{9}$ Aristides Hatzis $(2006,2015)$ explained why it is not only morally problematic but prudentially wrong policy to assign weight to moral externalities. Legal moralism, i. e. the prohibition of actions and practices opposed by dominant social mores, not only conflicts with J. S. Mill's harm principle ${ }^{10}$ but can be criticised within an amoral economic framework as well, by demonstrating that it leads to intractably high transaction costs. This research is relevant for our methodological purposes because it illustrates how far economic models can contribute to our understanding of moral costs. Apart from the substantive goal of criticising legal moralism and arguing for self-ownership in a roughly consequentialist way, Hatzis also pursued a methodological goal: "to rebut an economic argument for legal moralism by using another economic argument." (Hatzis 2015, 240).

Why should there be no right to interfere with another person's choices? Referring to Jensen and Meckling's distinction of physical and value effects ${ }^{11}$ and Holderness's arguments about open and closed classes of right-holders, ${ }^{12}$ Hatzis's main argument against assigning weight to moral externalities is that "the assignment of rights to the "moral majority" under the assumption that this would maximize total welfare undermines the Coasean dynamics because of the creation of open classes of right holders. The right to an "immoral behaviour" in particular is not a scarce right. Thus, exercising this right does not preclude anyone else from doing the same." 13 (Hatzis 2015, 240) The external effects that "immorality" can create are value effects, not physical effects. Such value effects ought not to be taken into account because of transaction costs; we should only assign rights to a closed and identifiable class of right-holders. Rightholders should have been assigned self-ownership, although they can then be bribed, in Calabresi's terms. Referring to the example of same-sex marriage: even if the majority have "moral preferences" against same-sex marriage, the right to marry should be assigned to each individual, including the moral minority. Whether the moral majority would be willing to pay what individuals in the minority demand for relinquishing their right is an empirical matter. Based on this analysis alone, Hatzis does not consider that such rights should be inalienable.

The technical details of this argument do not concern us here. More interesting is the point that while other L\&E scholars invoke existing laws (Posner and Sunstein 2017) or refer to non-welfarist moral arguments (Trebilcock 1993, 75) to limit the impact of moral externalities, Hatzis does not want to recur to non-consequentialist arguments based on rights and autonomy to draw a line - he thinks that economics itself is enough. Note, however, that his argument only applies to cases where the assignment of rights to a closed group is at stake. It does not rule out taking into account moral externalities in cost-benefit analysis in general.

In this section I provided some illustration to the point that when Calabresi argues for taking moral preferences into account in legal policy, his argument is not going against the grain of economics. In fact, many L\&E 
scholars have been thinking along similar lines for quite some time. Calabresi $(2016,133)$ rightly claims that we need self-consciousness and recognition in our dealing with tastes and values. Yet, elsewhere in the book it is unclear how these moral externalities should be "taken into account" and in what sense they "cannot be ignored" (Calabresi 2016, 74). Posner and Sunstein (2017) make very specific practical suggestions in this regard. Yet, if Hatzis's argument is correct then, even in welfarist accounts, moral externalities or moral preferences should not be the basis of granting rights.

This economic approach to tastes and values raises a number of questions, both theoretical and practical, which Calabresi has only hinted at. Does it make sense to take social norms or moral beliefs as variables in a welfare calculus? Should they be taken into account by an omniscient social planner or more realistically by administrative agencies? When is such an exercise analytically correct and practically helpful? What should be the criteria for declaring certain moral costs "off limit"? Finally, does such talk about morality in terms of preferences and costs inadequately flatten our moral landscape? In sum, Calabresi's line of argument raises and leaves open both analytical and normative questions. I shall come back to some of them in Section 3. But first, let me show that there are some good (pro tanto) reasons to be parsimonious in this exercise of accounting for values and tastes and to stick to some version of the homo oeconomicus model. These arguments go beyond the argumentative strategy of accepting the disciplinary status quo which seems to have, at least in part, motivated Calabresi's analysis of tastes and values in terms of "moral costs" (Calabresi 2017, 171-2). In this way, they provide a rationale for parsimony.

\section{Three arguments for parsimony}

In a now classic argument "against parsimony", Albert Hirschman suggested "three easy ways of complicating some categories of economic discourse", in order to provide richer accounts for phenomena such as preference change, non-instrumental activities and love (Hirschman 1984). In contrast, while not necessarily in contradiction, this section discusses three reasons "for parsimony" in economic models. ${ }^{14}$ These are considerations which may or may not have motivated Calabresi's strategy of using simple economic assumptions but they hopefully make a cogent and more analytically helpful argument for his case to enrich economics while remaining within a relatively narrow methodological paradigm.

First, there is an argument for economic models built on assumptions of rationality and self-interest, insofar as these assumptions are not only plausible but provide a good empirical approximation of how economic agents in fact behave. This may be true in a limited context or domain, for instance among sophisticated individual or collective agents acting professionally in market settings, where stakes are high yet there has been opportunity to learn, gather information and the incentives are conducive to profit-maximising behaviour. In such contexts, homo oeconomicus can be a good approximation of empirical data. Versions of this empirical argument for parsimonious models have been shared by economists since the nineteenth century, including Mill and Marshall or more recently Harold Demsetz (1997). This argument justifies parsimony only as far as empirical data support parsimonious models.

Second, there are logical or ontological reasons for modelling human behaviour in a way that assigns a "minimal" version of rationality to individuals. The core argument here is that economics as a social, rather than natural science needs to account for human behaviour and its consequences in non-naturalistic terms, i. e. in terms of beliefs, desires and intentions, rather than naturalistically, behaviourally, in narrowly causal or in evolutionary terms. These non-naturalistic accounts require what could be called minimal rationality. "Minimal" or "weak" rationality (Kirchgässner 2005) can be understood as a heuristic principle in accounts for purposeful human action (in contrast to causal explanations of non-human action as mere behaviour). This seems to be a (or perhaps the) distinguishing feature of methodological individualism, as well as the hallmark of the non-naturalistic character of economic models. Variants of this argument have been made by as diverse thinkers as Karl Popper, Ludwig von Mises and Philip Pettit (1995).

If human action is assumed or defined as rational, then empirical falsification is excluded. Mises's aprioristic theory of praxeology or what Robert Nozick (1977) called the "Austrian methodology" is strikingly similar to Popper's situational analysis and rationality principle (Hands 1985; Lagueux 1993). Similar arguments have been formulated by Becker (1976) in building a purportedly universal model for human behaviour, based on preference maximisation. In this Popperian-Beckerian view, what economists call the maximization hypothesis, and philosophers call the rationality principle is "a nonfalsifiable, yet a useful and nontautological metaphysical presupposition of the neoclassical research program" (Hands 1985, 93).

A distinct but related epistemic reason is concerned with the practice of theory-building or the logical order of explanation. Amartya Sen is right in saying that in a strictly logical sense when analysing human behaviour in a social scientific manner, there should not be an a priori bias toward (1) prudence against morality, (2) 
self-interest against altruism and (3) rationality against structural constraints. His view that evolutionary and reflective mechanisms are complementary is especially important (Sen 1998, xii-xiii). But this plurality does not exclude a certain primacy in the praxis of enquiry.

This is what the philosopher of social science, Jon Elster meant when arguing that the rational-actor theory is logically prior to its competitors (norm-oriented and structuralist approaches), though not necessarily more successful in each particular case (Elster 1984, viii-ix). The main reasons for this priority are not empirical or metaphysical, rather pragmatic: prudence, self-interest and rationality are simply convenient to be privileged as initial assumptions about human behaviour. More loosely, one could rephrase the second argument for parsimony thus: the explanation of social phenomena in terms of (1) rational (2) intentional (3) individual actions should enjoy heuristic primacy. For the pragmatic reasons of theory construction, these should be the starting point of analysis, without excluding that when we observe phenomena which can only be explained if one or more of these assumptions are relaxed, then this should be done.

Third, parsimonious models, in particular the assumption of self-interest can be justified by pragmatic reasons of institutional design. There is a venerable tradition in political philosophy and constitutional theory, with Hume and Kant as the best-known representatives, and the American Founding Fathers and the authors of the Federalist as classic examples, which states that we have good prudential, and perhaps even moral, reasons to design incentive-compatible or opportunism-proof institutions (Buchanan and Brennan 1985; Kornhauser 2002). Sometimes this argument is held to apply to the design of constitutions only but it is hard to see why the same logic would not apply at lower levels of institutional design just as well. One the one hand, incentivecompatibility requires that those who cooperate voluntarily, act virtuously or in a publicly beneficial manner are not at disadvantage. Even if free-riding and opportunism cannot be eliminated, the institutional designer should find ways to avoid that these individuals are exploited. He/she should design incentive-compatible institutions for large anonymous groups. On the other hand, this consideration provides an argument for parsimony to the extent that it suggests institutional designers not to expect individuals to be too virtuous or at least not rely on their virtue alone to sustain those institutions. To be sure, this is just a special case of a more general consideration, namely that the institutional designer should make such motivational (as well as epistemic and informational) assumptions about the actors concerned that best predicts their behaviour. Yet, this third argument is incomplete. Institutional design does not simply map human motivation in a static manner - it has an impact both on outward behaviour and arguably on motivation as well. I shall return to this point in the next section.

To summarise, empirical, epistemic and pragmatic arguments can be equally raised in favour of the parsimonious assumptions of economists, including rationality and self-interest. These are good pro tanto reasons for "quite traditional economic theory assumptions" (Calabresi 2016, 22) but they can be overridden by other reasons, as the next section argues.

\section{Arguments against parsimony}

The main argument advanced in this section is that each argument that can be mounted in support of parsimonious models has a corresponding anti-parsimonious argument. More specifically, my aim is to show that the agenda for economics suggested by Calabresi, which includes analysing both moral values and epistemic considerations in terms of preferences and costs, has some drawbacks.

One problematic aspect of parsimony concerns the way Calabresi treat values and tastes indistinctly. In Calabresi's overall argument, the issue of commodification is somewhat surprisingly connected to the category of merit goods ${ }^{15}$ and then operationalised in terms of moral preferences.

He discusses the distinction between values and tastes only briefly in a footnote (Calabresi 2016, 214 n 1) but ultimately does not pursue this distinction. Values are just a kind of taste. The economic models discussed above in Section 1 could all be called "reductionist" in the sense of saying that "in last analysis" moral behaviour is "nothing more" than preference satisfaction. What is wrong with or what do we lose by this reduction to a unidimensional calculus? After all, many social sciences treat moral views in a non-committed way, from an external perspective. And, arguably, "Democratic theory may support the notion that the state should put prevailing normative judgments into effect, and may also set the mechanisms for eliciting those judgments." (Zamir 2017, 116)

As a matter of moral phenomenology, it is worth emphasising that ordinary people tend to think about these two matters, tastes and values differently, for instance, considering how strongly they hold them and under what circumstances they are ready to scrutinise and revise them. Intuitively, it seems obvious that whether I prefer one flavour of ice cream over another (even if it is more expensive) or whether I support the death penalty (if it deters and because it deters to a certain degree) are categorically different questions. 
Using the category of "moral costs" to describe what people are "unhappy with, suffer from or object to" (Calabresi 2016, 42) or to say that it is just as futile to ask why people prefer the death penalty or same-sex marriage or voluntary armies as to ask why they prefer caviar or bananas (ibid. 74), i. e. that moral views only express preferences or desires or pro-attitudes, reduces complex normative issues into a one-dimensional costbenefit analysis. This flattening of the normative landscape glosses over important analytical and normative differences. As I see it, this "flattening of the normative landscape" is both analytically wrong and morally troubling.

As for analytical differences, this reductionist way of talking about values as tastes and moral commitments as costs conflates categories. This point has been made emphatically in the L\&E literature, in response to Kaplow and Shavell's discussion of moral arguments in terms of a "taste for fairness" (Kornhauser 2003, 116-122), and later raised by several critics in response to Calabresi (2016). As Eyal Zamir argued,

There is a fundamental difference between preferences and normative judgments. Individuals have the final say on the content of their preferences, but their judgments may be sound, or unsound. Whether a judgment is right or not depends on its justifications, not on the number of its supporters or the intensity of their support. (Zamir 2017, 116)

Judgements, including moral judgements, are, and should be, aggregated differently than preferences. Beliefs can be updated in response to new information and there is scope for rational argument about what is the case, in particular, what is the right course of action. This is clearly not the case with tastes for caviar or bananas, at least if tastes or preferences are understood as raw data about desires rather than judgements about their overall goodness. It is worth noting that these categorical differences hold even if one is a consequentialist and at least in the book Calabresi does not put forward a non-cognitivist meta-ethical view, indeed any meta-ethical view.

The conceptual innovation of "knowledge costs" illustrates what I shall call the epistemic drawbacks of parsimony. Referring back to his paper on "the pointlessness of Pareto" (Calabresi 1991), Calabresi introduces "knowledge costs" as another type of costs to be taken into account by economists and/or their addressees (Calabresi 2016, 147-51). Roughly speaking, these are the costs of generating and spreading economic knowledge. In motivating the idea of knowledge costs, Calabresi draws attention to the fact that economists do not include some moral costs in their cost-benefit calculation because it would be too costly to measure them with sufficient precision - a point well known in the practice of cost benefit analysis, see e. g. Posner and Sunstein (2017). In Calabresi's terminology, this very fact gives rise to a certain amount of knowledge cost. On further analysis, however, knowledge costs refer to a broad range of heterogeneous considerations: epistemic reasons applicable to theory building, features of the social institutions of knowledge production and information distribution, rhetorical techniques of rational and irrational persuasion, and more.

In Calabresi's parsimonious account all these diverse considerations come under the label of "knowledge costs." In this way, Calabresi's arguments easily become self-referential and hermetic: does his own theory take its own costs into account? And what is the matter if not? In short, if all that we know at this moment is that what keeps us at some unknowable distance from the best of all possible worlds are "costs", it is hard to see the analytical gain from this categorical innovation.

As we have seen in the previous section, parsimony can be defended on logical or epistemic grounds. Yet even explanatory versions of such parsimony or flattening can be opposed by epistemic arguments. In this vein, one could question the epistemic gains to be had from saying that "in last analysis", everyone is homo oeconomicus in all contexts - similar to what Stigler $(1982,35)$ claimed sometimes. This seems to devoid the notions of rationality and self-interest of any useful meaning. A more fruitful way to proceed would be to acknowledge a plurality of motivations and/or reasons and try to model them in a rigorous fashion. For instance, this could be done by saying that value-rationality in the Weberian sense is not a sophisticated version of instrumental rationality but something categorically different. This does not mean that it cannot be analysed in terms of lexicographic preferences - even though those preferences cannot be represented by standard utility functions. Similarly, traditional behaviour in the Weberian sense is better analysed as an evolutionarily stable strategy in terms of evolutionary game theory, rather than as instrumentally rational behaviour with high information costs.

Elster made a more general epistemic point against such reductions, in favour of respecting the diversity of reality.

On the one hand, "everything is what it is and not another thing." On the other hand, everything is a little bit like everything else. I firmly believe that science should be guided by the first principle, not by the second. Unless the analogy between A and B is based in a common causal theory, trying to understand B by using concepts and theories developed for the study of A is likely to fail. (Elster 1997, 752) 
To put it in (ultimately misleading) welfarist terms, it is not always clear what the benefits of such an exercise of parsimony are and whether these benefits override the costs. To be sure, there is something attractive in parsimony or reduction. Not only it suggests a sort of intellectual elegance or purity and in this sense caters to certain epistemic values; it may be psychologically attractive or seductive in a deeper sense as well:

If somebody can tell you that you need not bother about a certain aspect of reality because what is really going on is this, you have [been] admitted [...] to an inner circle of those who know What Is Really Going On; and we all know how immensely appealing that is. (Williams 2018, 23)

This idea already brings us from the analytical to the normative problems of parsimony. In this context, one has to ask what goals such a parsimonious modelling may serve and also what effect it may have in practice a question which brings us back to issues of legal or more broadly institutional design.

A key argument in this context concerns the performative effect of economic theories (MacKenzie, Muniesa, and Siu 2008) and the self-fulfilling character of their motivational assumptions. Crowding out (of non-selfish motivations) and performative effects (of homo oeconomicus models as being taught and imitated) may lead to perverse incentives against acting upon one's non-selfish motivation. If we turn homo oeconomicus into a model of human behaviour in policy design (something that, to repeat, we might have a reason to do, prima facie, if incentive-compatibility is an important concern), the result may be that more people think about themselves and behave as the model assumes them to be: (perhaps rational but more importantly self-interested) utilitymaximisers.

The performative effect of economic theory may be at play here is that agents are driven to act as they were predicted to. If we think and talk about human behaviour in terms of preferences and incentives, does it have an impact on the very behaviour, driving out less competitive motives? There is some empirical evidence about economics students being less willing to cooperate or show less public mindedness in terms of collective contributions than students of other subjects (Gerlach 2017). While such a performative effect is hard to praise, some see similar effects as entirely legitimate, even desirable. They argue that if L\&E scholarship is able to persuade business managers to look at their legal duties as costs, this is overall beneficial. "Managers do not have an ethical duty to obey economic regulatory law just because law exists. They must determine the importance of these laws. The penalties Congress names for disobedience are a measure of how much it wants firms to sacrifice in order to adhere to the rules; the idea of optimal sanctions is based on the supposition that managers not only may but also should violate the rules when it is profitable to do so." (Easterbrook and Fischel 1982, 1177 n 57) In most contexts, however, such performative effects of incentive-based regulation are highly problematic (Grant 2010). Assumptions about (ir)rationality in institutional design may also have an impact on learning from experience. In sum, the performative effects of economics suggest a potential practical (normative) argument against parsimonious models. The strength of this argument is largely an empirical matter.

To be sure, there are analytical exercises and empirical investigations where parsimony is not problematic. More precisely, there are practical contexts where economists do not have to take a stance on certain moral attitudes or values. They can do a completely adequate job by spelling out the consequences of these attitudes for institutional design, without taking a stance for or against them. One may adopt this view with the proviso that some foundational issues or normative premises are left unexamined. This is what could be called, in a different context, "middle theorising" (Calabresi 1984, 851).

In response to his critics, Calabresi acknowledges that there is an important difference between tastes and values, and admits that not all preferences should be given (equal) weight, morally or politically, but he leaves this at that. He refuses to engage in this discussion, claiming that these distinctions are not important for the argumentative purposes of the book which was to take on Lawyer Economists on their own premises about tastes and values. (Calabresi 2017, 171-3) In another context, Calabresi somewhat reluctantly acknowledges that the costs of theory are different from the costs in theory and economists are justified in focusing on the latter "in their everyday analysis" (ibid, 149). This can be seen as an implicit acknowledgement that these two categories are conceptually distinct.

In fact, recognising the limits of parsimony are, I believe, crucial for the success of Calabresi's overall project of enriching economics through real world experience. If this project is to be taken seriously and brought to fruition, not only is the raw material for theoretical analysis important to enriching economics (and, to note in passing, this material should be taken from human experience more broadly, not just the lawyer's experience), but the tools with which economists approach this material need to be adequate as well. Beyond the circle of economists or L\&E scholars, it is quite unlikely that one would suppose that it is mainstream or standard economics, as we know it, that will enlighten us about these vast areas of unanalysed human experience. In fact, at various stages, Calabresi himself refers to other social sciences such as Margaret Mead's anthropology or Peter Singer's comments on human socio-biology (Calabresi 2016, 207 n21, n23).

Despite such small signs of embracing diversity, Calabresi suggests including all instrumental/prudential (preferences, costs), moral (moral preferences and costs) and epistemic (knowledge costs or even rhetorical 
costs) considerations in a single dimensional calculus of "efficiency". This makes his enterprise look almost Benthamite. Given the rhetorical role assigned to Bentham in the opening chapter, such a change of roles would be perhaps baffling at first. On second look, it may be seen as a signal of Calabresi's subtle and characteristic sense of irony.

\section{Conclusion}

This paper provided some arguments for taking a "parsimonious" rational choice framework as a starting point for analysing human interactions. When one thinks about the pros and cons of subjecting human behaviour to economic analysis, there are three very different reasons for parsimonious behavioural assumptions. These suggest three different senses in which economic models need to be (and thus can fail to be) adequate: empirically, logically and normatively. Empirically, there are domains where rational decisions and/or self-regarding motivations are prevalent. Logically speaking, to account for human action in intentional, rather than causal terms, one needs to assume a certain "minimal rationality". Rational choice theory is able to model and explain, albeit with some loss in specificity, not just instrumentally rational but value-based or moral decisions as well. When motivational and informational assumptions about individuals are made in the context of institutional design, rationality and self-interest may be chosen counterfactually, for normative reasons. Depending on the context and on empirical variables not (yet, or ever) fully known, the reasons for parsimony can be countered with competing reasons against parsimony or at least against the kind of parsimony sometimes exercised. Thus, a parsimonious model fails empirically when its reference broad categories of preferences and costs make its predictions unfalsifiable; logically, when distinct conceptual categories are conflated; and normatively, when its implications or likely performative effects are normatively unacceptable.

\section{Notes}

1 Paolo Silvestri (2019), in this issue, analyses this problem in more detail.

2 A topic analysed by Marco Fabbri (2019), in this issue, in more detail.

3 Calabresi $(2016,205$ n5) refers to this article briefly but does not discuss its main achievements. Much of Becker's work in this area is collected in two volumes, The Economic Approach to Human Behaviour (Becker 1976) and Accounting for Tastes (Becker 1996),

4 For a thorough, critical review of Becker's work by a philosophically sophisticated proponent (and more recently, friendly critic) of rational choice theory in social science, see (Elster 1997). See also (Pies and Leschke 1998).

5 Calabresi $(2016,214 \mathrm{n} 1)$ cites another related paper by Cooter.

6 "Agencies have well-established tools for valuing risks to health, safety, and the environment. Sometimes, however, regulations are designed to protect moral values, and agencies struggle to quantify those values; on important occasions, they ignore them. That is a mistake. People may care deeply about such values, and they suffer a welfare loss when moral values are compromised. If so, the best way to measure that loss is through eliciting private willingness to pay." (Posner and Sunstein 2017,1)

7 Assume that John is one of those who care for the dolphins. "The ultimate goal of the Dolphin Protection Consumer Information Act is to protect dolphins, not John. But insofar as John's welfare is increased by the protection of dolphins, his willingness to pay is part of the cost-benefit analysis." (Posner and Sunstein 2017,3)

8 "[S]ome moral commitments cannot be counted in cost-benefit analysis, because the law rules them off-limits. It is also true that the principal reason to protect moral values is not to prevent welfare losses to those who care about them. But from the welfarist standpoint, those losses matter, and they might turn out to be very large. Agencies should take them into account. If they fail to do so, they might well be acting arbitrarily and hence in violation of the Administrative Procedure Act." (Posner and Sunstein 2017, 1)

9 Before coming to the analytical argument, Hatzis discusses Richard Posner's views on same-sex marriage. Posner opposed same-sex marriage in 2003 based on the apparent majority in the USA holding it to be immoral. Since then, and after the completion of Hatzis' papers, Posner changed his mind and at least in his judicial capacity defended same-sex marriage eloquently, in Baskin v. Bogan 766 F.3d 648 (7th Cir. 2014). When in 2015 he wrote a retrospective book review on this topic, he was also in favour, although explaining that the decisive argument for his change of mind has been the shift in public opinion (Posner 2015).

10 A topic discussed by Giovanni Tuzet (2019) in this issue.

11 "External effects can be classified into physical and value effects. An example of the first is physical pollution of a neighbour's farm; an example of the second is the introduction of a product that reduces a competitor's profits. The first is a social cost, because options have been physically eliminated from someone else's opportunity set. The second is not a social cost (although the wealth of the competitor declines) because no options have been eliminated and no real resources have been consumed." (Hatzis 2015, 236)

12 "[A]n open class in negative externalities (value external effects) is created when there are at least some individuals who can enter the class, and thus obtain rights, without first purchasing them from the natural owners. [...] If we give rights of moral protection to too many individuals (the whole society) by recognizing as harm the violation of conventional morality, the transaction costs for any hypothetical exchange will exceed the expected gains even if the rights are alienable." (Hatzis 2015, 239).

13 When discussing "Coasean dynamics", Hatzis refers to Calabresi's "best briber" solution to the normative Coase theorem, according to which the allocation of rights should be made in such a way "as to maximize the likelihood that errors in allocation will be corrected in the market" (Hatzis 2015, 238). This suggests that the sheer number of the moral minority qualifies them to be the (initial) right holders. 14 Hirschman $(1984,96)$ acknowledges that economists have "very good reasons" for parsimony, i. e. to focus on exogenous preferences, instrumental reasons and self-regarding motivations. Yet he suggests that certain features of human agency would need to be incorporated in economic models "for the sake of greater realism" and also to better "understand matter that have been found puzzling." While here, as elsewhere, Hirschman provides a spirited and insightful plea against parsimony, and my arguments in Section 3 are in accord with 
his ideas, his discussion of conceptual, methodological and normative arguments for and against parsimony are rudimentary: the tension between the above considerations for and against parsimony and the possible trade-offs between the epistemic virtues of parsimony and other virtues of "economic discourse" are not resolved at the level of theory-construction or in any other more abstract sense I am suggesting in Section 3 below.

15 See Maxime Desmarais-Tremblay (2019) in this issue.

\section{References}

Becker, Gary S. 1976. The Economic Approach to Human Behavior. Chicago: University of Chicago Press. Becker, Gary S. 1996. Accounting for Tastes. New York: Harvard University Press.

Buchanan, James M., and Geoffrey Brennan. 1985. The Reason of Rules: Constitutional Political Economy. Cambridge: Cambridge University Press. Calabresi, Guido. 1984. “First Party, Third Party, and Product Liability Systems: Can Economic Analysis of Law Tell Us Anything about Them?” lowa Law Review 69: 833-51.

Calabresi, Guido. 1991. “The Pointlessness of Pareto: Carrying Coase Further.” Yale Law Journal 100: 1211-37.

Calabresi, Guido. 2016. The Future of Law and Economics: Essays in Reform and Recollection. New Haven: Yale University Press.

Calabresi, Guido. 2017. "The Future of Law and Economics: Comments and Reflections." Jerusalem Review of Legal Studies 16 (1): 167-78.

Cooter, Robert 1998. "Model of Morality in Law and Economics: Self-Control and Self-Improvement for the "Bad Man" of Holmes." Boston University Law Review 18: 903-30.

Cooter, Robert. 2006. “The Intrinsic Value of Obeying a Law: Economic Analysis of the Internal Viewpoint." Fordham Law Review 75: 1275-85. Cserne, Peter. 2017. "Behavioural Law and Economics as Litmus Test." (Economia. History / Methodology / Philosophy 7 (3): 305-29.

Demsetz, Harold. 1997. “The Primacy of Economics: An Explanation of the Comparative Success of Economics in the Social Sciences.” Economic Inquiry 35 (1): 1-11.

Desmarais-Tremblay, M. 2019. “Calabresi on Merit Coods." Clobal Jurist 19 (3): 20180053. https://doi.org/10.1515/gj-2018-0053.

Easterbrook, Frank H., and Daniel R. Fischel. 1982. “Antitrust Suits by Targets of Tender Offers.” Michigan Law Review 80: 1155-78.

Elster, Jon. 1984. Ulysses and the Sirens: Studies in Rationality, 2nd ed. Cambridge: Cambridge University Press.

Elster, Jon. 1997. "More than Enough (review of Cary S. Becker (1996) Accounting for Tastes)." University ofChicago Law Review 64: 749-64.

Fabbri, M. 2019. "Shaping Tastes and Values Through the Law: Law and Economics Meets Cultural Economics." Global Jurist 19 (3): 20180051. https://doi.org/10.1515/gj-2018-0051.

Cerlach, Philipp. 2017. “The Games Economists Play: Why Economics Students Behave More Selfishly than Other Students." PloS One 12 (9). http://doi.org/10.1371/journal.pone.0183814.

Grant, Ruth W. 2010. Strings Attached: Untangling the Ethics of Incentives. Princeton: Princeton University Press.

Hands, Douglas W. 1985. "Karl Popper and Economic Methodology: A New Look." Economics and Philosophy 1: 83-99.

Harel, Alon. 2017. “Comments on the Future of Law and Economics." Jerusalem Review of Legal Studies 16 (1): 124-28.

Hatzis, Aristides N. 2006. "The Negative Externalities of Immorality: The Case of Same-Sex Marriage." Skepsis 17: 52-65.

Hatzis, Aristides N. 2015. "Moral Externalities: An Economic Approach to the Legal Enforcement of Morality." In Law and Economics: Philosophical Issues and Fundamental Questions, edited by Aristides N. Hatzis, and Nicholas Mercuro, 226-44. London: Routledge.

Hirschman, Albert O. 1984. "Against Parsimony: Three Easy Ways of Complicating Some Categories of Economic Discourse." American Economic Review 74: 89-96.

Kaplow, Louis, and Steven Shavell. 2001. "Moral Rules and the Moral Sentiments: Toward a Theory of an Optimal Moral System" Harvard Law and Economics Discussion Paper No. 342, http://ssrn.com/abstract=293906.

Kirchgässner, Gebhard. 2005. “The Weak Rationality Principle in Economics.” CESifo Working Paper No. 1410, http://SSRN.com/abstract=632981.

Kliemt, Hartmut. 1990. "Moral Externalities - External and Internal Sanctions." In Papers on Buchanan and Related Subjects, 37-60. München: Accedo.

Kornhauser, Lewis A. 2002. “Virtue and Self-Interest in the Design of Constitutional Institutions." Theoretical Inquiries in Law 3 (1).

Kornhauser, Lewis A. 2003. "Preference, Well-Being, and Morality in Social Decisions." Journal of Legal Studies 32: $303-29$.

Kübler, Dorothea. 2001. “On the Regulation of Social Norms." Journal of Law, Economics and Organization 17: 449-76.

Lagueux, Maurice. 1993. "Popper and the Rationality Principle." Philosophy of the Social Sciences 34 (4): 468-80.

MacKenzie, Donald, Fabian Muniesa, and Lucia Siu, eds. 2008. Do Economists Make Markets? on the Performativity of Economics. Princeton: Princeton University Press.

Nozick, Robert. 1977. "On Austrian Methodology." Synthese 36: 353-92.

Pettit, Phillip. 1995. “The Virtual Reality of Homo Oeconomicus." The Monist 78: 308-29.

Pies, Ingo, and Martin Leschke, ed. 1998. Cary Beckers ökonomischer Imperialismus. Tübingen: Mohr.

Posner, Eric. 2000. Law and Social Norms. Cambridge: Harvard University Press.

Posner, Eric A., and Cass R. Sunstein. 2017. "Moral Commitments in Cost-Benefit Analysis" University of Chicago Coase-Sandor Institute for Law 8 Economics Research Paper No. 802; U ofChicago, Public Law Working Paper No. 620, https://ssrn.com/abstract=2930450.

Posner, Richard A. 1998. Economic Analysis of Law, 5th ed. New York: Aspen Law\& Business.

Posner, Richard A. 2015. “Eighteen Years On: A Re-Review (of William N. Eskridge, Jr., The Case for Same-Sex Marriage: From Sexual Liberty to Civilized Commitment (1996))." Yale Law Journal 125: 533-42.

Rabin, Matthew 1993. "Incorporating Fairness into Game Theory and Economics." American Economic Review 83 (5): 1281-1302.

Sen, Amartya. 1998. "Foreword." In Economics, Values, and Organization, edited by Avner Ben-Ner, and Louis Putterman, vii-xiii. Cambridge: Cambridge University Press.

Shavell, Steven. 2002. “Law versus Morality as Regulators of Conduct.” American Law and Economics Review 4: $227-57$. 
Silvestri, P. 2019. "On the (Methodological) Future of Law and Economics. The Uneasy Burden of Value Judgments and Normativity." Global Jurist 19 (3): 20190026. https://doi.org/10.1515/gj-2019-0026.

Stigler, George ]. 1982. The Economist as Preacher. Oxford: Basil Blackwell.

Stigler, Ceorge ]., and Gary S. Becker. 1977. “De Gustibus Non Est Disputandum.” American Economic Review 67: 76-90.

Sunstein, Cass. R. 1996. “On the Expressive Function of Law.” University of Pennsylvania Law Review 144: 2021-53.

Trebilcock, Michael ]. 1993. The Limits of Freedom of Contract. Cambridge, Mass.: Harvard University Press.

Tuzet, G. 2019. “Calabresi and Mill. Bilateralism, Moral Externalities and Value Pluralism.” Clobal Jurist 19 (3): 20190012. https://doi.org/10.1515/gj-2019-0012.

Vanberg, Viktor ]. 2008. “On the Economics of Moral Preferences.” American Journal of Economics and Sociology 67: 605-28.

Williams, Rowan. 2018. Being Human: Bodies Minds, Persons. London: SPCK.

Zamir, Eyal. 2017. "Tastes, Values, and the Future of Law and Economics." Jerusalem Review of Legal Studies 16 (1): 101-23. 